\title{
DESCRIPTION OF A NEW SPECIES OF THYRSITOPS (T. VIOLACEUS) FROM THE FISHING-BANKS OFF THE NEW ENGLAND COAST.
}

\section{BB Y TARETTIN II. BBEAN.}

On the 7 th of November, 1887, the National Museum received from Mr. W. A. Wilcox, agent of the U. S. Fish Commission at Gloucester, Mass., two fresh fishes, a Blue Chimæra, C. affinis, and a species of Thyrsitops, which does not appear to agree with any of the described species. The latter was eaught by Capt. Thomas Thompson, schooner M. A. Baston, on Le Have Bank, in 125 fathoms.

The Thyrsitops is number 39287 of the fish register. It is 44 inches long to the base of the middle caudal rays. It is more nearly related to lepidopoides than to any other species; in fact, it is not very closely related to any of the others. If we may trust the figures and descriptions of $T$. lepidopoides our new species has a larger number of dorsal spines and rays and a much smaller number of dorsal and anal finlets. $T$. lepidopoides is said to be uniform silvery, the back somewhat plumbeous and the fins gray. Our species is uniformly purplish brown, the spinous dorsal, pectorals, ventrals, and inside of the mouth blackish.

The body is stout, its greatest width being exactly one-half of the height at the anal origin. The greatest height of the body is one-half of the length of the head, and is contained 8 times in the total length without caudal. The length of the head is one-fourth of the standard length; its greatest width is contained $4 \frac{1}{2}$ times in its length. The width of the interorbital area is slightly greater than the length of the eye, which is contained nearly $7 \frac{1}{2}$ times in the length of the head and $3 \frac{1}{2}$ times in the length of the upper jaw. The least height of the tail equals the width of the interorbital area. The length of the snout equals twice the length of the longest dorsal spine, and one-half the distance from the tip of the snout to the origin of the spinous dorsal. The maxilla extends to the vertical through the front of the eye. The length of the upper jaw equals $3 \frac{1}{4}$ times the width of the interorbital space. The mandible reaches to the vertical through the hind margin of the eye; its length, including the fleshy tip, is 5 times the width of the interorbital area The anterior nostril is smaller than the posterior; it is situated in advance of the eye one diameter of the eye. The posterior nostril is a narrow slit placed midway between the anterior and the eye. Strong teeth on the intermaxillary and mandible. Three large fangs anteriorly in the roof of the mouth; pseudobranchixe well developed; no trace of gill-rakers. The spinous dorsal begins at a distance from the snout, which equals twice the length of the snout; it is highest in the middle. The ninth and thirteenth spines are slightly longer than the third spine and more than twice as long as the twentieth, their length equaling one-half that of the snout. The soft dorsal is highest anteriorly, its longest ray, the fifth, being nearly twice the least height of the tail. The caudal is forked; its middle rays about one-half as long as the external

Proc. N. M. $87--33$ 
rays. The anal origin is under the third ray of the soft dorsal, its distance from the vent $2 \frac{1}{4}$ times the length of the dagger-shaped spine The vent is directly under the end of the spinous dorsal. The anal rays are longest anteriorly, the fifth ray being nearly as long as the corresponding ray of the soft dorsal. The dagger-shaped spine in front of the anal equals one-half the least height of the tail. The ventral is immediately under the third spine of dorsal; its first and longest ray equals three-fourths of the interorbital width. The fifth ray is about two-thirds as long as the first. The pectoral begins under the second dorsal spine; its length equals $2 \frac{1}{2}$ times the width of the interorbital area. It extends to the vertical midway between the fifth and sixth dorsal spines.

The lateral line is well developed; it descends gradually from the upper angle of the gill opening, reaching the median line of the body under the soft dorsal. The scales are irregular in shape, thin, elongate, cycloid, and deciduous.

Color, purplish. The spinous dorsal, pectorals, ventrals, and inside of mouth blackish.

D. XX, 1, $19+2$ finlets; A. $17+3$ finlets; V. I., 5 ; p. 13.

TABLE OF MEASUREMENTS.

$\mathrm{mm}$.

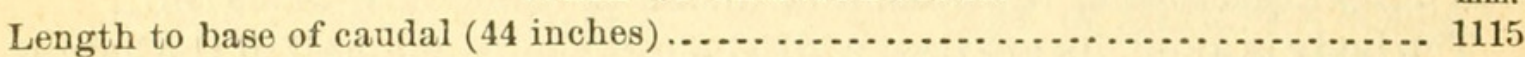

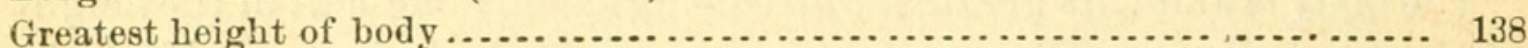

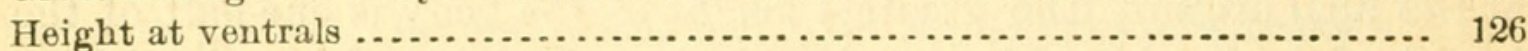

Height at anal origin ............................................... 112

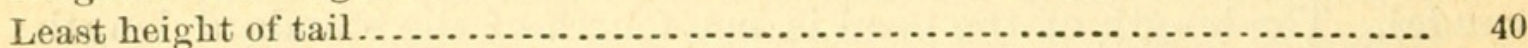

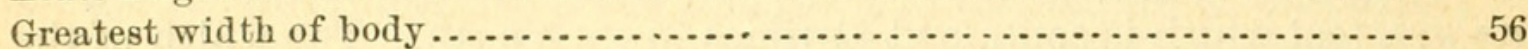

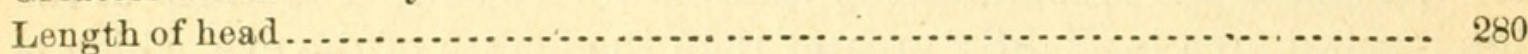

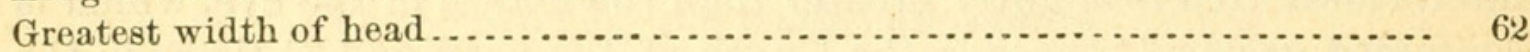

Width of interorbital area ........................................... 40

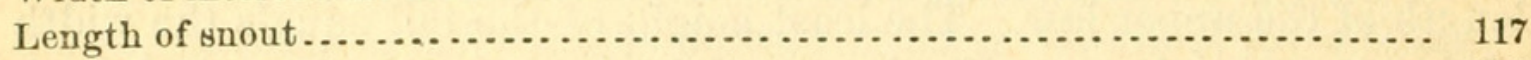

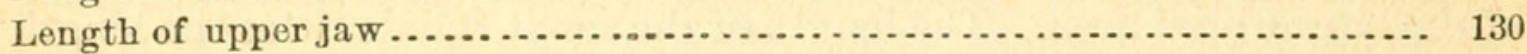

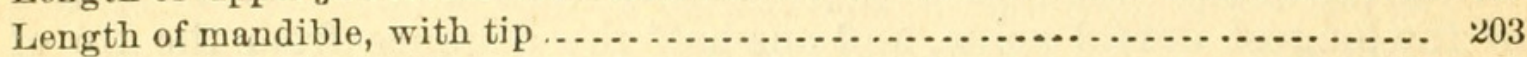

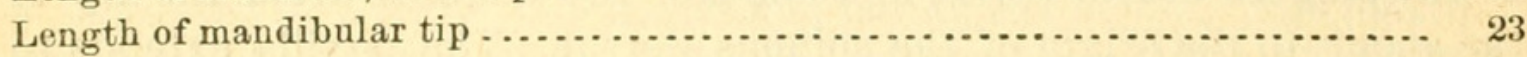

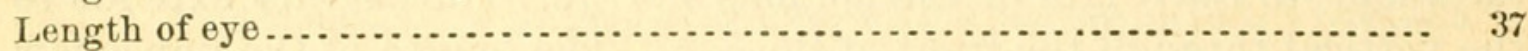

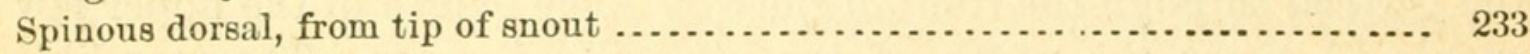

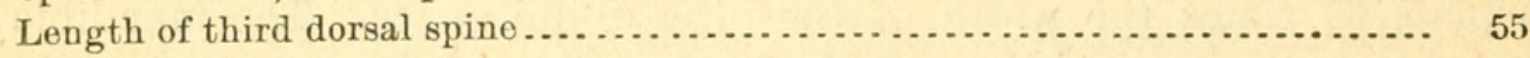

Length of ninth dorsal spine ......................................... 58

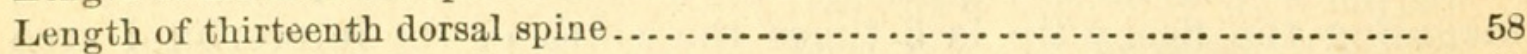

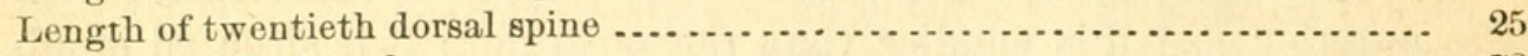

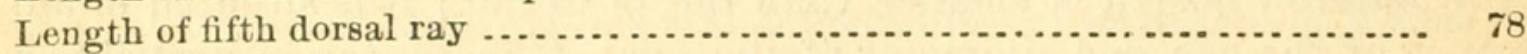

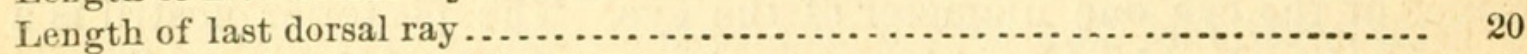

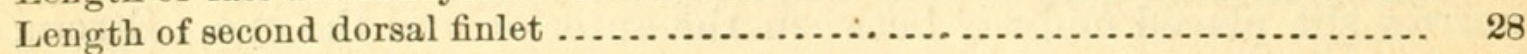

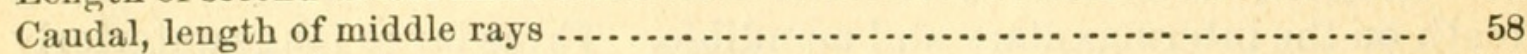

Caudal, length of external rays...................................... 116

Pectoral, from tip of snout .......................................... 255

Length of pectoral................................................. 100

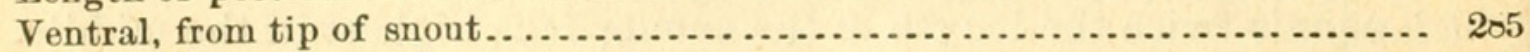

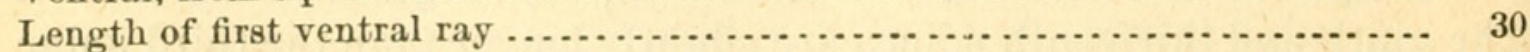

Length of fifth ventral ray .......................................... 22

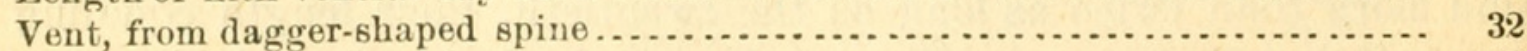

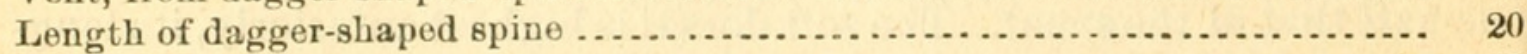

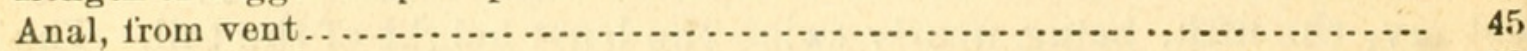

Length of fifth anal ray .............................................. $\tau_{2}$

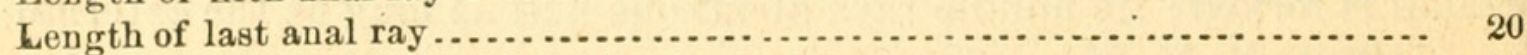

Length of last anal finlet............................................ 28 


\section{$2 \mathrm{BHL}$ Biodiversity Heritage Library}

Bean, Tarleton H. 1888. "Description of a new species of Thyrsitops (T. violaceus) from the fishing-banks off the New England coast." Proceedings of the United States National Museum 10(658), 513-514. https://doi.org/10.5479/si.00963801.10-658.513.

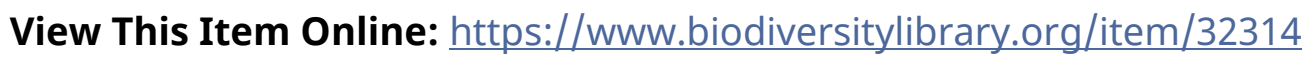
DOI: https://doi.org/10.5479/si.00963801.10-658.513

Permalink: https://www.biodiversitylibrary.org/partpdf/23748

\section{Holding Institution}

Smithsonian Libraries

\section{Sponsored by}

Smithsonian

\section{Copyright \& Reuse}

Copyright Status: NOT_IN_COPYRIGHT

This document was created from content at the Biodiversity Heritage Library, the world's largest open access digital library for biodiversity literature and archives. Visit BHL at https://www.biodiversitylibrary.org. 